\title{
Empirical analysis of university-industry R\&D collaboration: Evidence from Pakistan
}

\author{
Saqib Mehmood Afzal ${ }^{\mathrm{a}}$, Khawaja Farooq Ahmad $^{\mathrm{a}}$, Muhammad Imran Qureshi ${ }^{\mathrm{b}}$, Khalid Zaman ${ }^{\mathrm{a}^{*}}$ and \\ Naila Khan ${ }^{\mathbf{a}^{*}}$
}

${ }^{a}$ Department of Management Sciences, COMSATS Institute of Information Technology, Abbottabad, Pakistan ${ }^{b}$ Faculty of Management, Universiti Teknologi Malaysia, 81310 UTM Skudai, Malaysia

\section{H R O N I C L E}

Article history:

Received January 20, 2014

Accepted 5 July 2014

Available online

July 102014

Keywords:

$R \& D$ collaboration

University

Industry

Pakistan

\section{Introduction}

In the nation's innovation system, university-industry collaboration is an important social experiment and it has gained serious policy attention over the last two decades (Lee, 2000). Research and Development $(\mathrm{R} \& \mathrm{D})$ projects refer to those systematic innovative activities that result in more knowledge produced and utilized for developing new applications. In the U.S.A, due to budgetary limitations from government, many universities are seeking support of industries for R\&D projects. $\mathrm{R} \& \mathrm{D}$ collaboration between universities and industries is an innovative process that results in the development of new technologies and generates new ideas (Mansfield \& Lee, 1996). Apart from, university-industry R\&D collaboration, Government-University and Industry collaboration has also emerged in developed countries (Carayannis, et al., 1999). Research outputs of universities have powerful effects on the research activities of industrial sector. Universities not only assist industries in their new $\mathrm{R} \& \mathrm{D}$ projects but also contribute to already running R\&D projects of industries (Cohen, et al., 2002).

*Corresponding author. Cell : +92-334-8982744; Fax : +92-992-383441

E-mail addresses: khalidzaman@ciit.net.pk (K. Zaman) 
In developed countries like Japan, the collaboration of smaller firms with universities is rapidly increasing as compared to the larger firms. Larger firms seek their long term benefits and toughen their technology, whereas smaller firms take part in such efforts when the product has already completed its initial stages. Universities find an opportunity to commercialize their research work. In modern era, smaller and medium enterprises are more active towards these joint efforts as they lack financial and human resources. New technology based firms also show keen interest in such collaborations due to their requirement of management resources (Motohashi, 2005).

University-industry collaborative projects allow exchange of ideas among universities and industries, where both the parties have their own objectives besides the identical objectives. It is a form of beneficial relationship that fulfills the individual as well as collective needs of collaborating bodies and focuses on basic research activities (Lee, 2000). Successful collaborative activities are based on interests of both the parties, so that exchange of knowledge becomes smooth and easy (Fontana, et al., 2003). Partnership between university and industry is based on diffusion and sharing of knowledge between the partners. Firms size and their R\&D capabilities determine the type of this relationship and to what extent knowledge is exchanged between the two collaborating bodies (Fontana, et al., 2006).

In Pakistan, a study conducted show that universities and industries can collaborate in such a way that results in quality assurance and hence raise the quality of higher education through quality research outputs. The relationship between universities and industries has not developed very much due to different thoughts of the parties. Industries demand research in practical fields where as universities prefer research in their own respective fields. But with the passage of time, both industries and universities are realizing the increasing demand for their joint participation in research activities. Higher Education Commission of Pakistan initiated the "University-Industry Interaction (UII)" project in 2005.The primary objective is to strengthen the industries of Pakistan by building up a symbiotic relationship between academia and universities and providing a plat-form for collaborative research (Shaukat, 2009).

National University of Science and Technology (NUST) launched the Center for Energy Systems (CES) in 2011 for collaboration with industries in the projects relating to energy sector. CES takes part in projects both at national level and international level. Nationally, CES is collaborating with ICI, BASF, PSO, NOVA Energy, Infinity Engineering, Aynbee Group of Companies, AERO, DESCON, SNGPL \& Fiber Tech. At international level, CES is running joint projects with Canada, UK, USA, South Africa and China.

Lahore University of Management Sciences (LUMS) took a significant step by launching Research Initiative on Internet and Society (RIIS) which is viewed as self-supporting projects relating to internet and society. The primary focus of RIIS is to make more use of internet for social, economic and legal development of the society and develop a relationship between the society and the cyberspace. RIIS has signed a project with Google after one week of its foundation in the year 2012.The collaborated project Technology for People Initiative (TPI), has been funded by Google.

\subsection{Definitions}

Some important definitions are given below;

1.1.1. Firm Size: Fontana et al., 2006, defined it as an accumulative measure of;

- R \& D employment which determines the relative size of a particular firm

- The number of employees of the firm

- Annual budget of the firm 
1.1.2. Firm Innovation Activity: Fontana et al., 2006, defined it in terms of;

- Process innovation: It measures whether the focus is on innovation of processes

- Product innovation: It measures whether the focus is on product innovation

Both of above measure the effect of innovation processes on firm's ability to collaborate

1.1.3. Openness of the firm: Openness of the firm is defined as the way used to collect external information based on the number of channels of information which are used beneficially to import knowledge (Laursen \& Salter, 2003). It is the orientation of a firm to setup R\&D collaboration with firms (Fontana et al., 2004) and can be examined by three types of activities i.e., searching, screening, signaling as (Fontana et al., 2006);

i. Searching: This variable can be defined through the number of channels used by a firm to connect to the outside world. It indicates the willingness of a firm to relate with external world to gather knowledge for innovations.

ii. Screening: It shows the ability of a firm to filter the most appropriate and relevant information source for solving a technical issue faced by the firm. For example reading publications thoroughly and to remain in touch with new partners by taking part in government funded R\&D projects are the 'enablers' of screening mechanism.

iii. Signaling: It is the manner through which firms expose their competences to the outside world and the level to which they disclose their knowledge. Signaling is explained by patents which are used to protect imitation of an innovation.

\subsubsection{R\&D Collaboration}

$\mathrm{R} \& \mathrm{D}$ collaboration means research collaboration between public research organizations and industry in which industry oriented project supported either fully or partially by sponsoring firms (Lee, 2000).

\subsection{Research Objectives}

The present study is aimed at to study the following objectives:

- To analyze the university-industry collaborative R \& D projects.

- To measure the association of firm size, firm's innovation activity and openness of the firm with the university-industry collaboration for R\&D projects.

\section{Literature Review}

Firm size strongly influences R \& D partnerships which in turn are affected by the nature and scope of the R \& D project. Small and Medium Enterprises (SME) have both pros and cons of taking part in such a collaborative activity, usually they have financial barriers towards research costs, so its beneficial for them but on the other side, they face also difficulties in managing such huge bodies. But one thing that is common for both small and large firms is that costly and risky projects are determinants of such partnerships (Busom \& Ribas, 2008). Results of study conducted in Spain reveal that a firm's capability for R\&D innovation depends upon industry in which it operates. Firms that make huge investments in innovative activities have more tendency of successful and cooperative collaboration. Public administrations may offer public funding for internal R\&D activities of a firm and supporting innovative activities (Segarra-Blasco \& Arauzo-Carod, 2008).

In Japan, university-industry collaboration is gaining strength. Previously, the larger firms showed more tendency towards these collaborations as they have sufficient R\&D resources unlike the small firms. But the trend is changing now. Smaller firms are getting more benefits of the collaboration and increasing their levels of productivity as compared to larger ones because they lack human as well as 
financial resources for achieving their goals and seek university-industry collaborations with more practical and realistic goals like new product development instead of technology purchase. Due to rapid change in technology, in-house innovative efforts are becoming effective. To keep a dynamic process of innovation, there is felt a need for external collaboration (Motohashi, 2005). Research on Spanish firms and research organization shows that victorious partnerships are heavily impacted by factors from firms as well as research organizations. Previous links, commitment, definition of objectives and conflict are success factors from firm's side while research organizations communication, previous links, trust, commitment and the partners' reputation contribute a lot (MoraValentin et al., 2004).

Universities are a great source of change in industrial technology resulting in new products and processes development. Research conducted on seven industries; chemical, pharmaceutical, metal industries, electronic, instruments, petroleum and information processing, reveals that universities contributed a lot of their knowledge in the mentioned industries and supported them in industrial innovation. Firms seek for universities which can resolve their issues through basic and applied research activities (Mansfield \& Lee, 1996).

A significant roadblock for innovative firms is lack of financial support from public due to public policies which are not directed towards the R\&D. Collaborations with high quality international innovative networks provide firms with more advantages of funding for innovation as compared to the national level collaboration (Blasco et al., 2008).

A research study conducted in India shows that experienced firms show more rigorous attitude towards R\&D and are ready to make investments in multiple sources of technology, unlike the smaller and younger firms, which avoid such investments. This is due to the fact that smaller firms lack resources and information on available technologies. Medium sized firms are found to be the most active in R\&D. Import of technology results in increased profitability instead of relying on firm's own in-house R\&D. Firms where multiple technological sources are used, in house R\&D and import of technology are favorable for each other (Narayanan \& Bhat, 2009). R\&D activities are found to be significant determinants of firm's performance. Investments in R\&D and collaborations for technology sharing are the tools, which augment firm's core competencies. This enhancement in core competencies results in improved innovation capabilities, which generate more financial benefits for firms. R\&D investments, once made cannot be recovered again, so it is important to bring in-time innovation before it becomes abandoned. Intense $R \& D$ activities by firms result in price competitions in the market which deteriorate firm's profits and benefits (Sher \& Yang, 2005).

Although R\&D partnerships are meant to enhance performance of the firms, all partnerships are not successful. 14\% of R\&D collaborations fail or delay and cannot achieve their goals due to difficulties in partnerships. These difficulties are termed as "cooperation failures" and can be minimized through making investments in intensive R\&D and basic research. Collaborations with competitors and public research organizations (PROs) are more likely to face such failures, especially in case where one partner is foreign. Partnerships with customers and suppliers are more likely to succeed. Partnerships with universities are rising in number because huge investments are not required (Lhuillery \& Pfister, 2009). Research study on German manufacturing industry shows that number of collaborating partners in a partnership effect the innovative abilities of firms. Increase in the number of collaborators increases the probability of product innovation as chances of success are increased by working with each other. R\&D partnerships fulfill the deficiency of in-house resources for innovative activities. Extensive R\&D expenditures and improved methods of protecting internal knowledge base help in realizing a new product development. Size of the firm affects the firm innovation output as larger firms depict more efficiency in product innovations than the smaller firms. This is because larger firms have more diversification and international sales which significantly impact their product innovations (Becker \& Dietz, 2004). 
A focused study on the SMEs in selected seven countries of European Union (EU) showed that Public Research Organization (PROs) impart very little towards the innovation processes of SMEs. The sectors included chemicals, food and beverages, telecommunications services and computer services sectors. It is found that although PROs are not big contributors for SMEs innovative ideas but still half of the firms in the sample are collaborations with PROs. The size and openness of the firms determine their tendency to do partnerships with PROs and larger firms do more partnerships with PROs (Fontana et al., 2003). Knowledge transfer is a systematic process comprising of multiple steps. Three major steps are; knowledge creation, then its acquisition and the last one involves the integration of the acquired knowledge. These three activities can be done parallel to each other instead of doing in sequence (Santoro \& Gopalakrishnan, 2000).

Innovation capabilities provide strong competitive edge to a firm. Different firms have different pace of innovation. Firms make investment decisions based on the pool of resources available to them, as different firms have different resources and capabilities. Financial resources show inverse relationship with R\&D activities, more the financial resources; less will be the likelihood of R\&D activities. Significant predictors of internal R\&D are intangible factors, which have strategic importance and determine R\&D investments (Canto \& Gonza'lez, 1999). The existence of positive relationship between the introduction of product innovation and the extent of reliance on PROs is recorded (Mohen \& Hoareac, 2002). Innovation policies have their impact on R\&D partnerships and collaborations enhance firms innovation output. A comparative study made between Germany and Finland shows that in Finland, public R\&D subsidies and R\&D partnerships have positive impact on patent activity, which means an increased innovation output. While in Germany this is not the case where public subsidies do not foster patent activity and to increase the level of innovation output, additional motivational factors are to be used (Czarnitzki et al., 2004).

Contribution of universities towards innovation processes of firms cannot be underestimated. But as a matter of fact only certain firms are able to draw knowledge directly for their innovation activities. The firms having capability of openness for innovation activities are more likely to fall in the category of firms drawing knowledge directly from academia. Openness depends on the number of external channels of information used by firms to innovate; strategy regarding openness is search strategy (Lausren \& Salter, 2004). Universities are considered to play a critical role in knowledge production and transmission. The role of universities in economic development of country can never $\mathrm{b}$ under estimated. The interaction between university scientists and industries is through different means. These interaction channels can be grouped under five headings; training, consultancy and contract research, meetings and conferences, joint research and creation of new physical facilities. University researchers' percentage interacting with industries varies among different fields. Such interactions are common in UK. Research shows that university researchers' individual attributes determine their interactions with industries and are strongly involved than the organizational characteristics. Individual attributes that facilitate and result in more frequent interactions are past experience and academic rank. It is found that young researchers are getting heavily involved in interactions with industries (Este \& Patel, 2007).

This increasing academic support for R\&D may cause reduction in government funding and support. Firms taking the advantage of academic research should be aware of the fact that nearness of the firm to the place where academic research takes place has more economical benefits (Mansfield \& Lee, 1996). Issues for firms collaborating with academics are: to solve specific technical or design problems; to develop new products and processes; to conduct research leading to new patents; to improve product quality; to reorient R\&D agenda; to have access to new research via seminars and workshops; to maintain an ongoing relationship and network with the university; to conduct "blue sky" research in search of new technology; to conduct fundamental research with no specific applications in mind; to recruit university graduates (Lee , 2000). Knowledge transfer is related to organizational culture and structure. The firms with stable and mission-oriented culture have more 
likelihood of well established system for knowledge transfer. Such cultures support in attaining external knowledge. But surprisingly dynamic cultures also have no negative impact on knowledge institutionalization of knowledge transfer practices. It is observed that these two forms of culture are needed to exist together as the former facilitates knowledge acquisition and the later assists in knowledge creation and integration (Santoro \& Gopalakrishnan, 2000).

Studies conducted in the U.S.A show that the projects between universities and industries generate more knowledge about basic research, such projects face more trouble during their execution but there is more probability that they will achieve their goals and objectives and will not be stopped before completion. Unlike this fact, the partnerships without universities involvement are terminated soon. The projects with larger research funding have broader scope. Larger funding facilitates in acquiring knowledge and its incorporation. Projects related to chemicals, information technology, energy, and the environment have faster pace of commercialization than electronics, manufacturing and biotechnology projects (Hall et al., 2000).

A survey conducted in Belgium shows that industries having larger size and belonging to chemical/pharmaceutical sector take more interest in university-industry partnerships. Both universities and industries are ready to face the risk of initiating any particular R and D project (Veugelers \& Cassiman, 2005). The reasons for academics collaborating with industry are: to get funding for academic research work; test the practical assistance of one's own research; get more knowledge regarding one's own research; make progress for the university's outreach mission; search for a good business opportunity; gain knowledge about practical problems; generate job placement and student internships opportunities; obtain funding for research assistants and lab equipment (Lee, 2000).

Licensing agreements, start-ups and research joint ventures are different means of technology transfer between universities and industries. University industry Technology Transfer (UITT) is assisted by managerial skills and organizational behavior. There is significant margin of enhancing the effectiveness of the partnerships between the universities and the industries. Cultural factors of universities and policies for technology transfer should be flexible. Fostering informal relationships facilitates the UITT (Siegel et al., 2003).

Universities contribute to the production of knowledge and knowledge inputs in the business sector in three major ways. First, the business sector receives inputs from universities in the form of highly educated capital; second, by developing and providing new knowledge which is disseminated through publications and presentations; third, by developing and providing new knowledge through research which is disseminated through co-operative research projects or consultancy for the business sector (Schartinger et al., 2001). Firms which have past experience in patenting and R\&D capacity are active towards national R\&D programs. Whereas firms participating in European R\&D programs are not research intensive and have more inclination towards export. As university-industry R\&D partnerships require large amount of investments, therefore the firms that receive public grants for their R\&D activities usually have more chances of collaborating with the universities (Busom \& Ribas, 2004). Successful previous interaction enhances the likelihood of more collaboration with the business sector in the future but cultural clashes may cause hurdles in such partnerships. Another barrier in the success of university-industry collaboration is lack of information which is due to communication gap between the two bodies (Schartinger et al., 2001).

R\&D collaboration can be explained through tools that firms use for bringing in knowledge and ideas from the outside. Firms that are active in receiving public subsidies, patenting have more partnerships with PROs and thus more openness. Openness of the firm to the external environment results in more productive relationship between the two collaborating bodies (Fontana et al., 2003). 
Firms can contribute in aiding UITT through arranging frequent workshops to build up the cultural differences and hiring experts for working in collaboration with universities. Several factors that are preventing these effective collaborations are; inflexible administrators; lack of rewards for the university researchers; lack of technology transfer resources; strict intellectual property rights and poor marketing skills. Public sector universities are more vulnerable to the mentioned problems (Siegel et al., 2003). Although Pakistan is facing financial barriers, the country has realized the importance of human resource and thus making investments in the R\&D infrastructure. Huge R\&D up gradation is taking place in public sector specifically. R\&D investments for Higher Education Commission have increased tremendously during the recent years and have reached to Rs. 2000 million from Rs.530 million. The health, agriculture, engineering, industrial research and defense are highly focused fields. But still the percentage of scientists and engineers has not risen to a satisfactory level in the total population. Focus on continuous human resource development, building a culture of innovation in government organizations, encourage $R \& D$ collaborations between private firms and public universities, facilitating universities in knowledge creation and its transfer through building up business incubators, technology parks and providing access to venture capital are recommendations for improving the ratio of scientists and engineers and thus for economic growth (Hassan Shakeel \& Nawar Khan, 2007).

\section{Research Methodology}

\subsection{Sampling Techniques}

Purposive (non- probability) sampling technique is applied for the selection of sectors and then companies. The study area of this research comprised of all industrial sectors of Pakistan. Out of total 36 sectors located throughout the country, top 15 sectors are chosen according to their market capitalization. Of these sectors, top three companies from each sector are selected for the present study as per follows: This information is collected from the Karachi Stock Exchange official website (www.kse.com) and each company's official websites.

\section{Sectors and Companies Location (Head Office)}

1. Automobile and Parts

i. Atlas Honda Limited

ii. Atlas Battery Limited

iii. Dewan Farooque Motors Limited

2. Beverages

i. Murree Brewery Company Limited

ii. Shakarganj Foods Limited

iii. Shezan International Limited

3. Chemicals

i. Fauji Fertilizer Company Limited

ii. Dewan Salman Fibre Limited

iii. Ghani Glasses Limited

4. Commercial Banks

i. Allied Bank Limited

ii. Askari Bank Limited

iii. Bank Al-Falah Limited

5. Construction and Materials (Cement)

i. D.G. Khan Cement Company Limited

ii. Fauji Cement Company Limited

iii. Bestway Cement Limited

6. Electricity

i. Hub Power Company Limited
Karachi

Karachi

Karachi

Rawalpindi

Lahore

Lahore

Rawalpindi

Islamabad

Lahore

Lahore

Rawalpindi

Lahore

Lahore

Rawalpindi Cantt.

Islamabad

Karachi 
ii. General tech Pakistan Limited Karachi

iii. Altern Energy Limited Lahore

7. Electronic and Electrical Goods

i. Climax Engineering Company Limited Gujranwala

ii. Johnson and Phillips (Pakistan) Limited Islamabad

iii. Pakistan Cables Limited

8. Engineering

i. Al-Ghazi Tractors Limited

ii. Dewan Automotive Engineering Limited

iii. Millat Tractors Limited

9. Equity Investment Instruments

i. Allied Rental Modarba

ii. First Habib Bank Modaraba

iii. Crescent Standard Modaraba

10. Financial Services

i. Arif Habib Investment Limited

ii. First National Equities Limited

iii. Dawood Capital Management Limited

11. Fixed Line Telecommunication

i. Pak Datacom Limited

ii. Pakistan Telecommunication Company Limited

iii. Wateen Telecom Limited

12. Food Producers

i. Abdullah Shah Ghazi Sugar Mills Limited

ii. Adam Sugar Mills Limited

iii. Al-Abbas Sugar Mills Limited

13. Forestry (Paper and Board)

i. Century Paper and Board Mills Limited

ii. Pakistan Paper Products Limited

14. General Industrials

i. Cherat Packaging Limited

ii. Ecopack Limited

iii. Packages Limited

15. Health Care Equipment and Services

i. Medi Glass Limited

ii. Shifa International Hospitals Limited
Abbottabad

Islamabad

Lahore

Islamabad

Karachi

Islamabad

Karachi

Karachi

Karachi

Karachi

Islamabad

Islamabad

Lahore

Lahore

Karachi

Karachi

Karachi

Karachi

Karachi

Hattar

Lahore

Lahore

Islamabad

The 15 sectors which are chosen for the study show the representativeness of the study area which makes $41.67 \%$ of the total population. This proportion shows that the sample is representative of the whole population.

\subsection{Participants}

The middle and top level management of the companies of selected sectors of Pakistan make the participants in this study. The survey was conducted on random basis taking responses through questionnaires without any discrimination or biasness. Questionnaires were distributed along with a briefing given to the potential respondents in the form of personal discussions. It is a cross-sectional study as the data has been collected only once. It is expected, that all respondents have provided the response honestly and correctly up to their understanding and comprehension of the questionnaire. 


\subsection{Questionnaire Development}

The questions are based on standardized questionnaire (Fontana et al., 2006) with some modifications. It is designed to gather information regarding all the variables. The hypotheses designed for this study are:

\subsection{Hypotheses}

- H1: Firm's size has a positive impact on university-industry collaboration for R\& D projects.

- H2: Number of employees has a positive relationship with university-industry collaboration for R\&D projects.

- H3: Annual budget of the firm has a positive impact on university-industry collaboration.

- H4: Firm's innovation activity has positive impacts on university-industry R\&D collaboration.

- H5: Openness of the firm has significant impact on collaboration for R\& D projects.

\subsection{Conceptual Framework}

The model is based on the theoretical framework provided by Fontana et al., 2006. It is designed to explore the impact of firm's size, innovation activity and openness on the collaboration between universities and industries for R\&D projects. Fig. 1 shows the research framework of the study.

Independent variables

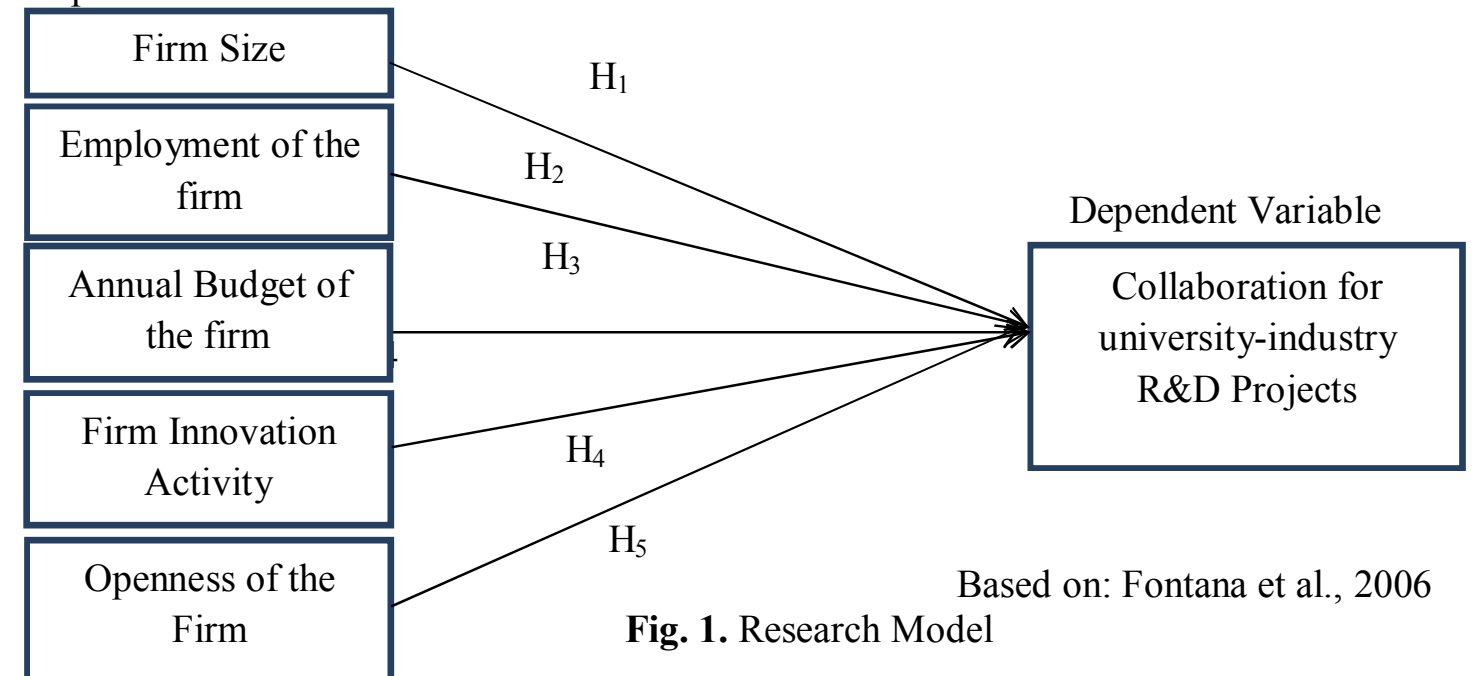

\subsection{Data collection and response rate}

A total of 157 questionnaires were used for data collection and data was collected through personal visits, emails and telephone as per following details:

\subsubsection{Personal visits}

Out of 157 questionnaires, 107 were contacted through personal visits. Of these, 87 respondents responded with the response rate of $81 \%$ whilst overall response rate was $79 \%$.

\subsubsection{E-mail}

Out of 157 questionnaires, 46 were sent through e-mails. Of these, 22 respondents responded with the response rate of $48 \%$ whilst overall response rate was $20 \%$. 


\section{Results}

\subsection{Reliability analysis of the variables}

In the current study, reliability means consistency of the set of measurements and the term describes to what extent each item was reliable to measure the true response. Table 1 shows the reliability statistics of the questionnaires.

Table 1

Reliability Statistics

\begin{tabular}{cc}
\hline Cronbach's Alpha & N of items \\
\hline 0.807 & 35 \\
\hline
\end{tabular}

A higher value of Cronbach's coefficient means more reliability and 0.7 is taken as threshold value (Nunnally, 1978). Table 1 show the impact on the whole value of Cronbach's coefficient, mean and variance if any item is deleted. For example, the above table shows that if we delete the variable firm size in question one then the overall value of Cronbach's alpha becomes .807, which is a reliable measurement. All the variables have Cronbach's values in significant range which are acceptable.

\subsection{Reliability Analysis of firm size}

Reliability test is performed on firm size to test whether the constructs that are being used are able to measure firm size are reliability or not. Cronbach Alpha value for firm size is .719. Findings are mentioned in Table 2.

Table 2

Reliability Statistics for Firm Size

\begin{tabular}{cc}
\hline Cronbach's Alpha & No of Items \\
\hline .719 & 6 \\
\hline
\end{tabular}

\subsubsection{Reliability Analysis of firm innovation activity}

Reliability test is performed on firm innovation activity to test whether the constructs that are being used to measure firm innovation activity are reliable or not. Cronbach Alpha value for of firm innovation activity is .780. Findings are mentioned in Table 3.

Table 3

Reliability Statistics for firm innovation activity

\begin{tabular}{cc}
\hline Cronbach's Alpha & N of Items \\
\hline .780 & 9 \\
\hline
\end{tabular}

\subsubsection{Reliability analysis of openness of the firm}

Cronbach's alpha's value for openness of the firm is 0.727 which depicts the reliability of the construct. Table 4 shows the reliability statistics.

Table 4

Reliability Statistics for openness of the firm

\begin{tabular}{cc}
\hline Cronbach's Alpha & N of Items \\
\hline .727 & 14 \\
\hline
\end{tabular}




\subsubsection{Reliability Analysis of Collaboration for university-industry $R \& D$ projects}

Cronbach's Alpha value is .702 for collaboration for University-industry R\&D Projects which is an acceptable range. Sivanand et al. (2004) described that if alpha value is more than 0.5 , it shows that the scale used can be considered reliable. Table 5 shows the reliability statistics for university $-\mathrm{R} \& \mathrm{D}$ projects.

Table 5

Reliability Statistics for $R \& D$ projects

\begin{tabular}{cc}
\hline Cronbach's Alpha & N of Items \\
\hline .702 & 6 \\
\hline
\end{tabular}

\subsection{Descriptive analysis of the variables}

Descriptive statistics deal with the concepts and methods concerned with summarization and explanation of the important aspects of the statistical data. This area of the study consists of the summarizing of data, their graphical displays and the calculation of a few statistical quantities that provide information about the center of the data i.e. mean and indicate the spread of the observed data i.e. dispersion. Table 6 and 7 shows the descriptive statistics of concerned variables.

Table 6

Descriptive statistics

\begin{tabular}{lccccc}
\hline Variable & $\mathrm{N}$ & Minimum & Maximum & Mean & Std. Deviation \\
\hline Firm size & 111 & 1.33 & 4.67 & 3.2423 & .80180 \\
Firm innovation & 111 & 1.00 & 4.50 & 3.1846 & .89750 \\
Openness of the firm & 111 & 1.00 & 4.75 & 3.1826 & .71063 \\
Collaboration & 111 & 1.00 & 5.00 & 3.0224 & .82631 \\
Valid N (list wise) & 111 & & & & \\
\hline
\end{tabular}

Table 7

Descriptive Statistics of Demographics

\begin{tabular}{lccccc}
\hline \multicolumn{1}{c}{ Variable } & $\mathrm{N}$ & Minimum & Maximum & Mean & Std. Deviation \\
\hline Firms total employment & 44 & 75.00 & 575000.00 & 39871.6136 & 1.23391 \\
R\&D employment & 44 & 0.00 & 75.00 & 7.1591 & 14.39952 \\
Annual Budget & 44 & 5.00 & 37419.00 & 2283.3182 & 6567.53348 \\
Budget spent on R\&D & 44 & 0.00 & 100.00 & 6.4602 & 17.37948 \\
Number of R\&D projects completed & 44 & 0.00 & 15.00 & .5000 & 2.37722 \\
Valid N (list wise) & 44 & & & & \\
\hline
\end{tabular}

Firm's total employment is considered as demographic variable. Minimum value for firm's total employment is 75 and maximum value is 575000, an average value is 39871.6136 and standard deviation is 1.23391. R\&D employment is also considered as demographic variable. Minimum value for $\mathrm{R}$ and $\mathrm{D}$ employment is .00 and maximum value is 75 , average value is 7.1591 and standard deviation is 14.39952. Annual budget is also considered as demographic variable. Minimum value for Annual budget is 5 and maximum value is 37419 , average value is 2283.3182 and standard deviation is 6567.53348. Budget spent on R\&D is also considered as demographic variable. Minimum value for budget spent on R\&D is .00 and maximum value is 100, average value is 6.4602 and standard deviation is 17.37948. Number of R\&D projects is also considered as demographic variable. Minimum value for number of $R \& D$ projects is .00 and maximum value is 15.00 , average value is .5000 and standard deviation is 2.37722 .

4.5 Correlation analysis of the variables 
Correlation shows the relationship between the variables how strongly variables are related to each other. Table 8 shows the correlation analysis of the variables which is measured by Pearson correlation and two tailed test is used to check the significance level.

Table 8

Correlation

\begin{tabular}{|c|c|c|c|c|c|c|c|}
\hline & & Firm Size & Firm innovation & Openness & Collaboration & Employee & Budget \\
\hline \multirow[t]{3}{*}{ Firm Size } & Pearson Correlation & 1 & & & & & \\
\hline & Sig. (2-tailed) & & & & & & \\
\hline & $\mathrm{N}$ & 111 & & & & & \\
\hline \multirow{3}{*}{ Firm Innovation } & Pearson Correlation & $.393 * *$ & 1 & & & & \\
\hline & Sig. (2-tailed) & .000 & & & & & \\
\hline & $\mathrm{N}$ & 111 & 111 & & & & \\
\hline \multirow[t]{3}{*}{ Openness } & Pearson Correlation & .147 & $.404 * *$ & 1 & & & \\
\hline & Sig. (2-tailed) & .125 & .000 & & & & \\
\hline & $\mathrm{N}$ & 111 & 111 & 111 & & & \\
\hline \multirow[t]{3}{*}{ Collaboration } & Pearson Correlation & $.250 * *$ & $.637 * *$ & $.620 * *$ & 1 & & \\
\hline & Sig. (2-tailed) & .008 & .000 & .000 & & & \\
\hline & $\mathrm{N}$ & 111 & 111 & 111 & 111 & & \\
\hline \multirow[t]{3}{*}{ Employee } & Pearson Correlation & $.201 *$ & $.445^{* *}$ & $.370^{* *}$ & $.560 * *$ & 1 & \\
\hline & Sig. (2-tailed) & .034 & .000 & .000 & .000 & & \\
\hline & $\mathrm{N}$ & 111 & 111 & 111 & 111 & 111 & \\
\hline \multirow[t]{3}{*}{ Budget } & Pearson Correlation & .101 & $.436 * *$ & $.508^{* *}$ & $.299 * *$ & $.329 * *$ & 1 \\
\hline & Sig. (2-tailed) & .289 & .000 & .000 & .001 & .000 & \\
\hline & $\mathrm{N}$ & 111 & 111 & 111 & 111 & 111 & 111 \\
\hline
\end{tabular}

**. Correlation is significant at the 0.01 level (2-tailed).

*. Correlation is significant at the 0.05 level (2-tailed).

From the above table, it is observed that correlation coefficient value between firm size and firm innovation activity is positive and medium i.e. with the increase in firm size; firm innovation activities also increase to a certain extent. There exists a positive but weak association between the variables firm size and firm openness of the firm. Firm size and R\&D collaboration have correlation coefficient 0.250 ; there is positive but weak correlation between the two variables. Correlation coefficient between firm size and number of employees is also positive but weak. Firm size and annual budget are weakly positively associated to each other and correlation coefficient is 0.101 .

Correlation coefficient between firm innovation and openness of the firm is positive and medium correlation. Firm innovation and R\&D collaboration are positively strongly correlated to each other. Number of employees has positive and medium correlation coefficient towards firm innovation having a value of 0.445 while annual budget too has positive and medium association with firm innovation.

Openness of the firm and R\&D collaboration have a positive strong correlation and more the firm's openness of the firm, more will be the firm's R\&D collaboration. Number of employees and openness of the firm of the firm have a positive but medium correlation coefficient. Annual budget of the firm depicts very strong positive correlation with the openness of the firm and both go side by side, when annual budget increases, openness of the firm increases too.

R\&D collaboration and number of employees are very strongly positively correlated. R\&D partnerships also increase with the increase in number of employees. Unlike this, R\&D collaboration is weakly but positively correlated to annual budget of the firm. Number of employees has medium positive association with the annual budget. Table 9 shows the multiple regression. 
Table 9

Regression analysis of the variables

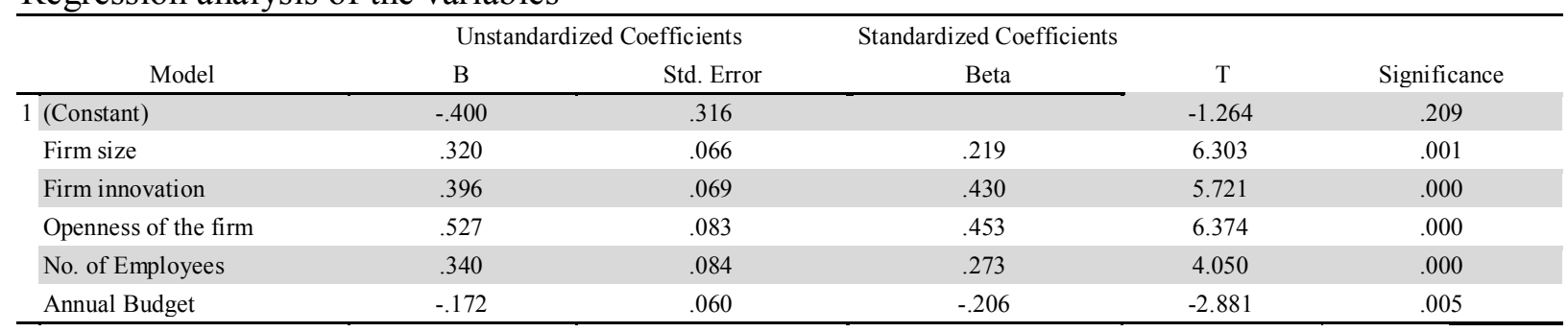

a. Dependent Variable: Collaboration

R-Square: 0.641; Adjusted R-square: 0.612; F- statistics: 35.251; F-prob. 0.000

There exist a positive relationship between firm size and collaboration. Co-efficient of firm size is .320 and $\mathrm{p}$ value is .001 which is less than 0.05 which support the hypothesis. There exist a positive relationship between firm innovation and collaboration. Co-efficient of firm innovation is .396 and $\mathrm{p}$ vane is .000 , which is less than 0.05 , which support the hypothesis. There exist a positive relationship between openness of the firm and collaboration. Co-efficient of the openness of the firm is .527 and $p$ value is .000 , which is less than 0.05 , which support the hypothesis. There exist a positive relationship between number of employees and collaboration. Co-efficient of number of employees is .340 and $\mathrm{p}$ value is .000 , which is less than 0.05 , which supports the hypothesis. There exist a negative relationship between annual budget of the firm and collaboration. Co-efficient of annual budget is -1.72 and $p$ value is .005 , which is less than 0.05 , which dose not support the hypothesis. Table 10 shows the summary of the results.

\section{Table 10}

\section{Hypotheses Results}

$\mathrm{H}_{1} \quad$ Firm's size has a positive impact on university-industry collaboration for R\&D projects. Accepted

$\mathrm{H}_{2} \quad$ Number of employees has a positive relationship with university-industry collaboration for R\&D Accepted projects.

$\mathrm{H}_{3} \quad$ Annual budget of the firm has a positive impact on university-industry collaboration. Rejected

$\mathrm{H}_{4} \quad$ Firm's innovation activity has positive impacts on university-industry R\&D collaboration. Accepted

$\mathrm{H}_{5} \quad$ Openness of the firm has significant impact on collaboration for R\& D projects. Accepted

\section{Discussion}

On the basis of above results, hypotheses could be concluded with the following discussion:

The research model for the current study has been adopted from the previous works on the similar subject. Detail of the hypothesis generated from the model is given in the coming paragraphs.

\section{$H_{1}$ : Firm's size has a positive impact on university-industry collaboration for $R \& D$ projects}

Larger size firms have more tendencies for $R \& D$ collaboration with universities or government labs which have intensive R\&D activities, ability to attract skilled researchers and assign an appropriate portion of their budget for innovative partnerships with universities are ready to reap benefits of R\&D collaborations (Mohen \& Hoareau, 2002).

The chances of collaboration are less for smaller firms due to their less absorptive capacity and lower intensity of R\&D capabilities unlike the larger firms which have more absorptive capacity and are more R\&D intensive and thus, more oriented towards collaborative agreements with universities (Arundel \& Geuna, 2004). Larger firms have more likelihood of R\&D collaborations (Fontana et al., 2004; Fontana et al., 2006) because they have more resources which are exploited to take more advantages of such collaborations with PROs, whereas smaller firms lack sufficient resources to establish multiple partnerships with universities and PROs (Fontana et al., 2004). 
Firm's size when measured by the number of employees is a strong determinant of their participation in R\&D collaborations. Larger the number of employees in firm, smaller the number of qualified employees is expected, which results in more propensity to take part in such partnerships to achieve sufficient level of R\&D activities (Mohen \& Hoareau, 2002). Size of the firm influences R\&D collaborations but instead of taking absolute measure of size it should be measured as 'relative size' which is taken as total $R \& D$ employment which represents the R\&D intensity of a firm (Fontana et al., 2004).

\section{$H_{3}$ : Annual budget of the firm has a positive impact on university-industry collaboration (Rejected)}

The statement that larger firms have more resources, more R\&D projects and hence more capabilities of getting collaboration's benefits is contradictory as well (Fontana et al., 2004) Although larger size firms are found to be more active in R\&D collaborations between universities and firms, smaller firms yield more returns in such collaborations. Higher rates of return for smaller firms are due to their more capability of knowledge transfer than larger firms. Larger firms are found to be less efficient in taking advantages of R\&D partnerships and have lower productivity in terms of R\&D (Link \& Rees, 1990) because larger firms have more spending on their fixed costs as they have participated in so many R\&D projects (Cohen \& Klepper, 1996).

\section{$H_{4}$ : Firm's innovation activity has positive impacts on university-industry $R \& D$ collaboration}

Firms that invest on their R\&D resources are more competent in absorbing knowledge outside of their boundaries (Cohen and Levinthal 1990; Fontana et al., 2004) and this capability increases with the increase in firm size. Larger the firm size greater is the likelihood of R\&D collaborative projects with PROs and hence, of more university-industry R\&D collaboration. R\&D intensive firms are at the edge of science and technology which fosters their R\&D partnerships with public sources of knowledge (Fontana et al., 2004).

Innovations can be in the form of process innovations, product innovations or both types of innovations (Klevorick et al., 1995). Studies conducted in European countries observed that there exists a positive relationship between the innovation activities of the firm and R\&D collaboration (Mohen \& Hoareau, 2002). The firms involved in process innovation have more probability of establishing R\&D partnerships with public resources (Swann, 2002) likewise the firms which are more inclined towards universities for R\&D co-operation are those which are active at product innovation (Laursen \& Salter, 2003).

\section{$H_{5}:$ Openness of the firm has significant impact on collaboration for $R \& D$ projects}

Openness defines the attitude a firm uses to open up R\&D partnerships with PROs. Results of a study conducted on a sample of US based industries yield that customers, suppliers and other sources of information which have more direct and close links to the firms contribute significantly as sources of innovation by incorporating innovative ideas for R\&D projects (Fontana et al., 2004). Usually the firms which disclose their competencies and are heavily engaged in screening their outside environment have more inclinations for collaborating with academia. Firms which are energetic and vigorous in absorbing and scanning their outside environment are more probable participants of R\&D collaborations. Screening aids in initiating R\&D collaborative projects between SMEs and PROs while signaling strategy determines the intensity of the relationship between the two bodies (Fontana et al., 2006). 
The tendency of a firm to rely on an external source of information or to establish collaboration is determined by the type of innovation activity a firm pursues. The firms which are engaged in process innovations are more oriented towards R\&D collaborations with PROs and universities (Swann, 2002). Scientific \& business publications, patent databases and participation in conferences are important sources of external information. Patents act as means of inducing firms to establish R\&D partnerships with universities and provide a mechanism which facilitates firms in disclosing their internal knowledge to the external world (Fontana et al., 2004).

\section{Conclusion}

On the basis of the results, the following conclusions are made:

i. Firm's size has positive impact on university-industry collaboration for R\&D projects which shows that larger firms have more tendencies for R\&D collaboration with universities which have intensive $\mathrm{R} \& \mathrm{D}$ activities, ability to attract skilled researchers and assign an appropriate portion of their budget for innovative partnerships with universities and are ready to reap benefits of R\&D collaborations.

ii. Number of employees has positive impact on university-industry collaboration for R\&D projects which depicts that larger the number of employees in the firm, results in more tendency to take part in collaboration with universities to achieve sufficient level of R\&D activities.

iii. The results showed that there is no sufficient evidence that annual budget of the firm has positive impact on university-industry collaboration. Larger firms are found to be less efficient in taking advantages of R\&D collaboration with universities because larger firms have more spending on their fixed costs as they have participated in so many R\&D activities.

iv. It is found that firm's innovation activity has positive impact on university-industry R\&D collaboration which depicts that firms that invest on their R\&D resources are more competent in absorbing knowledge outside of their boundaries and this capability increases their productivity.

On the basis of the results, the following recommendations are made:

i. Since firm size has positive relationship with university-industry R\&D collaboration, so universities should focus on firms having larger size for R\&D collaboration.

ii. Since firms' innovation activity has positive relationship with university-industry R\&D collaboration, so universities should search for firms which are doing more innovative activities as compared to other firms.

iii. Openness of the firm has direct relationship with university-industry R\&D collaboration, so universities should target the firms which are more open towards their external environment having more number of external channels and more searching, screening and signaling activities.

The results drawn from the present study have certain limitations which could not be overcome due to lack of resources and time:

- Since the study is focused more towards industry side, a separate study particularly focused on university can also be undertaken to determine R\&D collaboration.

- This is an extensive study taking into account multiple sectors; however, a separate independent study can also be undertaken on a particular sector to find out R\&D collaboration to have better results in depth particular to that sector. 


\section{References}

Busom, I., \& Ribas, A.F. (2004). Firm Strategies in R\&D: Cooperation and Participation in R\&D Programs. Research Policy, 33, 209-223.

Busom, I., \& Ribas, A.F. (2008). The impact of firm participation in R\&D programmes on R\&D partnerships. Research Policy, 37, 240-257.

Canto, J.G.D., \& Gonza'lez, I.S. (1999). A resource-based analysis of the factors determining a firm's R\&D activities. Research Policy, 28, 891-905.

Carayannis, E. G., Alexander, J., \& Ioannidis, A. (2000). Leveraging knowledge, learning, and innovation in forming strategic government-university-industry (GUI) R\&D partnerships in the US, Germany, and France. Technovation, 20(9), 477-488.

Czarnitzki, D., Ebersberger, B., \& Fier, A. The Relationship between R\&D Collaboration, Subsidies and Patenting Activity: Empirical Evidence from Finland and Germany, 22, 1347-1366.

D'Este, P., \& Patel, P. (2007). University-industry linkages in the UK: What are the factors underlying the variety of interactions with industry? Research policy,36(9), 1295-1313.

Fontana, R., Geuna, A., \& Matt, M. (2003). Firm size and openness: the driving forces of universityindustry collaboration. SPRU, SEWPS, (103), 1-31.

Fontana, R., Geuna, A., \& Matt, M. (2006). Factors affecting university-industry R\&D projects: The importance of searching, screening and signalling. Research policy, 35(2), 309-323.

Lee, Y. S. (2000). The sustainability of university-industry research collaboration: an empirical assessment. The Journal of Technology Transfer,25(2), 111-133.

Mansfield, E., \& Lee, J. Y. (1996). The modern university: contributor to industrial innovation and recipient of industrial R\&D support. Research policy,25(7), 1047-1058.

Mora-Valentin, E. M., Montoro-Sanchez, A., \& Guerras-Martin, L. A. (2004). Determining factors in the success of R\&D cooperative agreements between firms and research organizations. Research Policy, 33(1), 17-40.

Santoro, M. D., \& Gopalakrishnan, S. (2000). The institutionalization of knowledge transfer activities within industry-university collaborative ventures.Journal of engineering and technology management, 17(3), 299-319.

Schartinger, D., Schibany, A., \& Gassler, H. (2001). Interactive relations between universities and firms: empirical evidence for Austria. The Journal of Technology Transfer, 26(3), 255-268.

Segarra-Blasco, A., \& Arauzo-Carod, J. M. (2008). Sources of innovation and industry-university interaction: Evidence from Spanish firms. Research Policy,37(8), 1283-1295.

Siegel, D. S., Waldman, D. A., Atwater, L. E., \& Link, A. N. (2003). Commercial knowledge transfers from universities to firms: improving the effectiveness of university-industry collaboration. The Journal of High Technology Management Research, 14(1), 111-133.

Veugelers, R., \& Cassiman, B. (2005). R\&D cooperation between firms and universities. Some empirical evidence from Belgian manufacturing. International Journal of Industrial Organization, 23(5), 355-379. 